\title{
Dosage compensation plans: protein aggregation provides additional insurance against aneuploidy
}

\author{
Rahul S. Samant, ${ }^{1,3}$ Vincent B. Masto, ${ }^{1,3}$ and Judith Frydman ${ }^{1,2}$ \\ ${ }^{1}$ Department of Biology, ${ }^{2}$ Department of Genetics, Stanford University, Stanford, California 94305, USA
}

Gene dosage alterations caused by aneuploidy are a common feature of most cancers yet pose severe proteotoxic challenges. Therefore, cells have evolved various dosage compensation mechanisms to limit the damage caused by the ensuing protein level imbalances. For instance, for heteromeric protein complexes, excess nonstoichiometric subunits are rapidly recognized and degraded. In this issue of Genes \& Development, Brennan et al. (pp. 1031-1047) reveal that sequestration of nonstoichiometric subunits into aggregates is an alternative mechanism for dosage compensation in aneuploid budding yeast and human cell lines. Using a combination of proteomic and genetic techniques, they found that excess proteins undergo either degradation or aggregation but not both. Which route is preferred depends on the half-life of the protein in question. Given the multitude of diseases linked to either aneuploidy or protein aggregation, this study could serve as a springboard for future studies with broad-spanning implications.

Missegregation of chromosomes in dividing cells, which gives rise to aneuploid daughters, generally reduces overall fitness and is unsurprisingly associated with a host of developmental defects (Oromendia and Amon 2014). However, aneuploidy is common in cancer cells and is linked to poor outcomes, including recurrence, metastasis, and multidrug resistance (Sansregret and Swanton 2017). This is likely linked to the ability of aneuploidy to drive phenotypic adaptation: Despite reducing cell proliferation and fitness, aneuploidy promotes acquisition of new traits and phenotypes. Previous work from the Amon laboratory (Oromendia and Amon 2014) linked the deleterious effects of aneuploidy to the accumulation of misfolded proteins and an ensuing proteotoxic stress. This may be linked with the near-universal induction of chaperones and stress responses in cancer (Calderwood and Gong 2016). Accordingly, adaptive aneuploidy (i.e., the

[Keywords: aneuploidy; protein aggregation; protein homeostasis]

${ }^{3}$ These authors contributed equally to this work.

Corresponding author: jfrydman@stanford.edu

Article is online at http://www.genesdev.org/cgi/doi/10.1101/gad.329383. 119. initial transient duplication of individual chromosomes in response to cellular stresses followed by recovery from aneuploidy by sampling more refined solutions) appears to be a protective mechanism for restoring protein homeostasis (Yona et al. 2012). Clearly, the relationship between aneuploidy, stress, and fitness is multifaceted. A better understanding of their complex interplay could uncover a strategy to render aneuploid cancer cells sensitive to treatments targeting their vulnerable proteomes.

One commonly observed phenotype of both aneuploidy and proteotoxic stress is the accumulation of protein aggregates. Protein aggregation-thought to be caused by proteins misfolding into a $\beta$-sheet-rich amyloid state-is a hallmark of aging-related protein misfolding diseases (Sontag et al. 2017). However, much like aneuploidy, the role of protein aggregates in cellular and organismal fitness is a matter of some debate. Although long thought to represent the pathogenic agents of these diseases, aggregates could instead serve as cytoprotective sites for quarantine of more toxic oligomeric species that occur earlier in the aggregation process (Escusa-Toret et al. 2013). Resolving this issue is critical for driving the progress of therapeutic interventions in protein misfolding diseases, especially for those that involve changes in aggregation as biomarkers of response.

Given the uncertainty surrounding the role of both aneuploidy and protein aggregation with respect to cellular fitness and disease pathology, Brennan et al. (2019) in this issue of Genes \& Development tackle head-on why aneuploidy results in widespread protein aggregation. Starting with a set of budding yeast strains with duplications in one of the organism's 16 chromosomes ("disomes"), the investigators used differential centrifugation combined with SILAC (stable isotope labeling by amino acids in cell culture)-based mass spectrometry (MS) to identify the proteins that aggregated in each of these strains. Promisingly, the investigators found an increase in both total protein aggregation and specific aggregation

(C) 2019 Samant et al. This article is distributed exclusively by Cold Spring Harbor Laboratory Press for the first six months after the full-issue publication date (see http://genesdev.cshlp.org/site/misc/terms.xhtml). After six months, it is available under a Creative Commons License (Attribution-NonCommercial 4.0 International), as described at http://creativecommons.org/licenses/by-nc/4.0/. 
of proteins encoded by the duplicated chromosome in almost all 16 strains. The overwhelming majority of proteins that aggregated in all strains were components of ribosomes, an observation consistent with several recent reports linking the aggregation of ribosomal proteins with proteotoxic stresses (Pathak et al. 2017; Sacramento et al. 2019; Tye et al. 2019).

Aside from ribosomes, the investigators ruled out numerous intrinsic protein features as being enriched in the aneuploid aggregates, including intrinsically disordered regions and primary sequence hydrophobicity. Proteins annotated as being components of stress granules were also not overrepresented. However, they did find an overlap between the proteins that aggregated in aneuploid cells and those that aggregated upon other proteotoxic stresses, suggesting that aneuploidy does trigger the aggregation of metastable proteins that are generally prone to misfolding.

Next, they switched focus to proteins in the aggregates that were encoded by the amplified chromosome. One might expect these proteins to be most directly affected by the increase in gene dosage. The investigators found that proteins encoded by the disomic chromosomes were enriched in aggregates from these strains. This observation also held true in human epithelial cells with an extra copy of chromosome 12 or chromosome 21, albeit more modestly than in yeast.

In the case of trisomy 21, which causes Down syndrome, it is thought that many gene dosage effects are compensated for through posttranslational degradation of excess proteins (Liu et al. 2017). This seems to occur at the level of heteromeric protein complexes in which different subunits are encoded by different chromosomes. Therefore, in the absence of corresponding extra subunits of their binding partners, extra subunits from the amplified chromosome result in their turnover, thus maintaining protein complex stoichiometry and, ultimately, proteostasis. The fact that numerous proteins misfold when interaction with their binding partners is prevented (e.g., the tumor suppressor Von-Hippel-Lindau) (EscusaToret et al. 2013) suggests that stoichiometry-based protein degradation is a common mechanism for dosage compensation in eukaryotes.

If aggregation is an alternative mechanism for dosage compensation, there should be a significant enrichment of heteromeric protein complex subunits that are encoded on the amplified chromosome when compared with the same category in nonamplified chromosomes. This is indeed what the investigators found (Fig. 1A,B). In a convincing set of mechanistic follow-up experiments, the investigators showed that aggregation of the eIF2 complex member Gcd11 in cells disomic for its encoding chromosome can be rescued if a single copy of that gene is deleted or by heterologous expression of its two binding partners. Therefore, at least for Gcd11 but presumably for other disome-encoded complex subunits too, aggregation is specific to increased copy number and is not due to general proteotoxic stress caused by aneuploidy.

In the final part of their study, Brennan et al. (2019) showed that most disome-encoded protein complex sub- units were either degraded or aggregated but rarely both. So, how does a cell decide whether to degrade an excess protein or sequester it in an aggregate? Maintaining focus on heteromeric complexes, the investigators found a correlation between protein half-life and aggregation propensity, suggesting that longer-lived subunits are triaged by aggregation, whereas shorter-lived ones are degraded (Fig. 1C). Surprisingly, this held true even when comparing subunits of the same complex with different half-lives. Therefore, the triage decision appears to be made at the level of the individual protein independently of the protein complex to which it belongs. These findings raise the fascinating and fundamental challenge of identifying the intrinsic (e.g., biophysical or structural features) and extrinsic (e.g., chaperone interactions or ubiquitination patterns) determinants of whether a misfolded protein will be degraded or aggregate.

The correlation between protein half-life and aggregation propensity draws parallels with determinants for different pathways of protein degradation: Short-lived proteins are processed through the ubiquitin-proteasome system, and longer-lived proteins are targeted to the lysosome (Ciechanover and Kwon 2015). Linking these two observations, it would be interesting to see whether the protein aggregates observed in this study would eventually be cleared by lysosomal degradation (e.g., through bulk or selective autophagy). It is also likely that the triage decision is influenced by relative actions of various molecular chaperones. Addressing these issues will be especially relevant for aging-related protein misfolding diseases, as many of these components-proteasome activity, lysosomal acidity, and molecular chaperone levels-decline during aging and are linked to disease pathology (Sontag et al. 2017). Therefore, aggregation may be especially important for dosage compensation in aged cells. Interestingly, small heat-shock proteins, which are thought to serve a cytoprotective proaggregation role, are actually up-regulated in many misfolding diseases. Testing whether down-regulating small heat-shock proteins in disomic strains changes the balance between aggregation and degradation and how this affects cellular fitness could help address many of the mechanistic questions posed by this study.

This study also brings to the fore another phenomenon observed during cancer but also during aging: the loss of protein complex stoichiometry (Janssens et al. 2015). Ribosomes (the major components aggregating in the present study) are especially sensitive to this, as shown by a recent study in turquoise killifish, where ribosomal subunits were enriched in aggregates from aged brains (Sacramento et al. 2019). Recent advances in global protein complex profiling techniques (e.g., size exclusion chromatography [SEC]-sequential window acquisition of all theoretical mass spectra [SWATH]-MS) (Heusel et al. 2019) will undoubtedly prove fruitful for characterizing protein stoichiometry changes under such conditions. In a similar vein, centrifugation or gel filtration-based proteomics (Geladaki et al. 2019) could be used to address whether proteins resident in certain subcellular compartments are especially prone to aggregation. One study found 
A Euploid cell

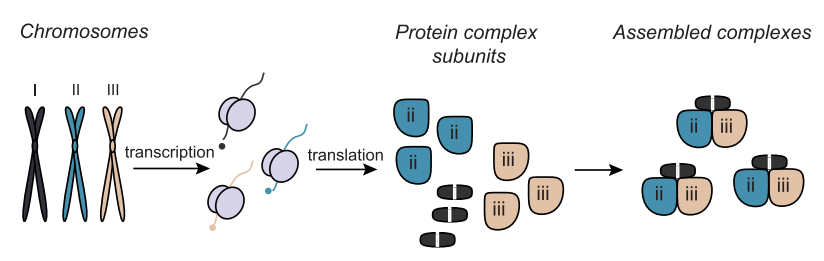

C

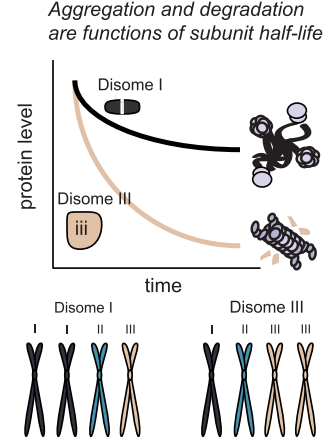

B Aneuploid cell

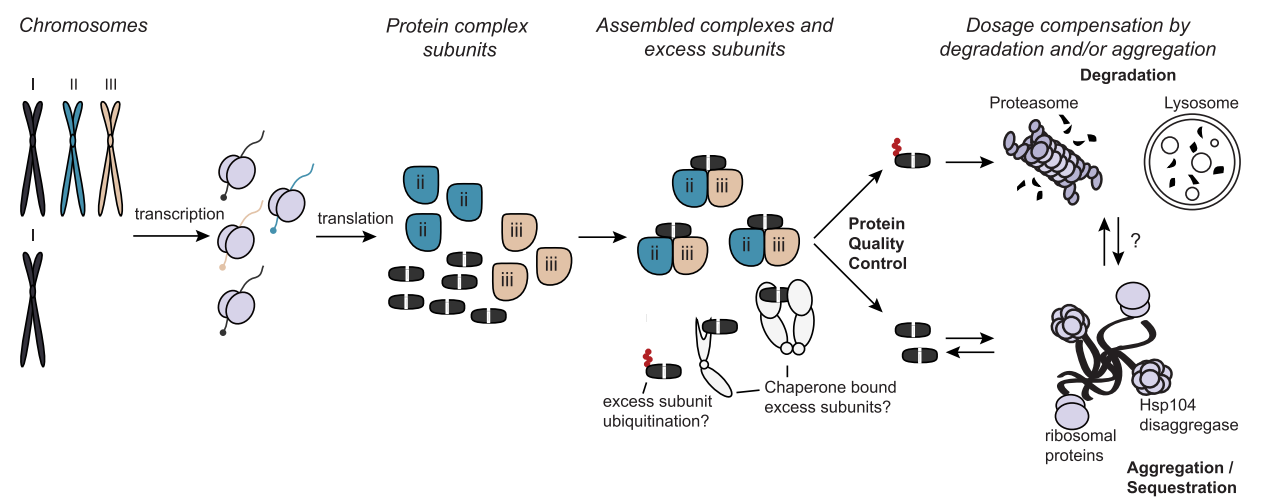

Figure 1. Model of aggregation as a dosage compensation mechanism in aneuploid cells. $(A)$ In euploid cells, protein complex subunits encoded on different chromosomes are produced at homeostatic levels, promoting complex assembly. (B) Additional copies of chromosomes in the aneuploid state result in a chronic proteotoxic stress partially due to substoichiometric subunits produced directly from genes encoded on the extra chromosome (chromosome I). The substoichiometric subunits engage cellular protein quality control pathways leading to degradation or aggregation. $(C)$ The investigators show that the fate of a substoichiometric subunit depends on its half-life.

that excess members of the hetero-octameric oligosaccharyl transferase complex in the endoplasmic reticulum (ER) are degraded by the ER-associated degradation machinery (Mueller et al. 2015). Perhaps protein aggregation is less prevalent in the ER and other organelles. Finally, future studies must resolve whether cells have different mechanisms for limiting toxicity from proteins in homomeric complexes or in heteromeric complexes where all of the complex members are on the same chromosome or, indeed, from singleton proteins not normally part of stable complexes, thereby providing a more complete picture of cellular responses to mitigate the proteotoxic stress triggered by aneuploidy.

\section{Acknowledgments}

All of the authors were supported by grants to J.F. from the National Institutes of Health (R01GM074074). R.S.S. was supported by a Human Frontier Science Program long-term fellowship (LT000695/2015-L). V.B.M. was partially supported by the National Institutes of Health (5T32GM007276-42).

\section{References}

Brennan CM, Pontano Vaites L, Wells JN, Santaguida S, Paulo JA, Storchova Z, Harper JW, Marsh JA, Amon A. 2019. Protein aggregation mediates stoichiometry of protein complexes in aneuploid cells. Genes Dev (this issue). doi:10.1101/gad .327494 .119

Calderwood SK, Gong J. 2016. Heat shock proteins promote cancer: it's a protection racket. Trends Biochem Sci 41: 311-323. doi:10.1016/j.tibs.2016.01.003

Ciechanover A, Kwon YT. 2015. Degradation of misfolded proteins in neurodegenerative diseases: therapeutic targets and strategies. Exp Mol Med 47: e147. doi:10.1038/emm.2014.117

Escusa-Toret S, Vonk WIM, Frydman J. 2013. Spatial sequestration of misfolded proteins by a dynamic chaperone pathway enhances cellular fitness during stress. Nat Cell Biol 15: 1231-1243. doi:10.1038/ncb2838

Geladaki A, Kočevar Britovšek N, Breckels LM, Smith TS, Vennard OL, Mulvey CM, Lilley KS. 2019. Combining LOPIT with differential ultracentrifugation for high-resolution spatial proteomics. Nat Commun 10: 331. doi:10.1038/s41467018-08191-w

Heusel M, Bludau I, Rosenberger G, Hafen R, Frank M, BanaeiEsfahani A, Aebersold R. 2019. Complex-centric proteome profiling by SEC-SWATH-MS. Mol Syst Biol 15: e8438. doi: $10.15252 / \mathrm{msb} .20188438$

Janssens GE, Meinema AC, González J, Wolters JC, Schmidt A, Guryev V, Heinemann M. 2015. Protein biogenesis machinery is a driver of replicative aging in yeast. Elife 4: e08527. doi:10 $.7554 /$ eLife.08527

Liu Y, Borel C, Li L, Müller T, Williams EG, Germain P-L, Aebersold R. 2017. Systematic proteome and proteostasis profiling 
in human trisomy 21 fibroblast cells. Nat Commun 8: 1212. doi:10.1038/s41467-017-01422-6

Mueller S, Wahlander A, Selevsek N, Otto C, Ngwa EM, Poljak K, Gauss R. 2015. Protein degradation corrects for imbalanced subunit stoichiometry in OST complex assembly. Mol Biol Cell 26: 2596-2608. doi:10.1091/mbc.E15-030168

Oromendia AB, Amon A. 2014. Aneuploidy: implications for protein homeostasis and disease. Dis Model Mech 7: 15-20. doi:10.1242/dmm.013391

Pathak BK, Mondal S, Banerjee S, Ghosh AN, Barat C. 2017. Sequestration of ribosome during protein aggregate formation: contribution of ribosomal RNA. Sci Rep 7: 42017. doi:10 $.1038 /$ srep42017

Sacramento EK, Kirkpatrick JM, Mazzetto M, Sanzo SD, Caterino C, Sanguanini M, Ori A. 2019. Reduced proteasome activity in the aging brain results in ribosome stoichiometry loss and aggregation. bioRxiv doi:10.1101/577478

Sansregret L, Swanton C. 2017. The role of aneuploidy in cancer evolution. Cold Spring Harb Perspect Med 7: a028373. doi:10 $.1101 /$ cshperspect.a028373

Sontag EM, Samant RS, Frydman J. 2017. Mechanisms and functions of spatial protein quality control. Annu Rev Biochem 86: 97-122. doi:10.1146/annurev-biochem-060815-014616

Tye BW, Commins N, Ryazanova LV, Wühr M, Springer M, Pincus D, Churchman LS. 2019. Proteotoxicity from aberrant ribosome biogenesis compromises cell fitness. Elife 8: e43002. doi:10.7554/eLife.43002

Yona AH, Manor YS, Herbst RH, Romano GH, Mitchell A, Kupiec M, Pilpel Y, Dahan O. 2012. Chromosomal duplication is a transient evolutionary solution to stress. Proc Nat1 Acad Sci 109: 21010-21015. doi:10.1073/pnas.1211150109 


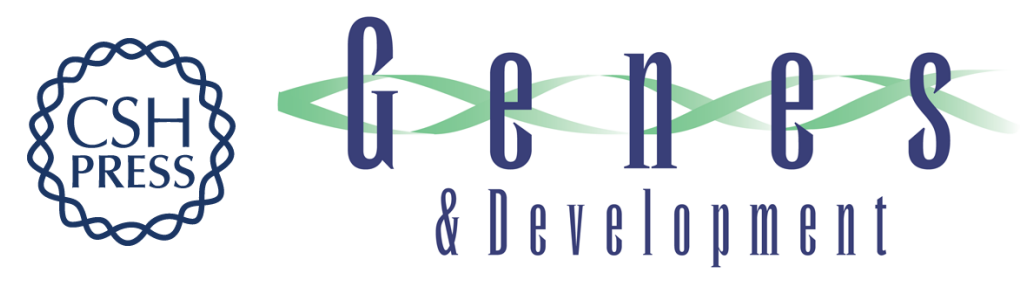

\section{Dosage compensation plans: protein aggregation provides additional insurance against aneuploidy}

Rahul S. Samant, Vincent B. Masto and Judith Frydman

Genes Dev. 2019, 33:

Access the most recent version at doi:10.1101/gad.329383.119

\section{Related Content}

References

Creative Commons License

\section{Email Alerting} Service
Protein aggregation mediates stoichiometry of protein complexes in aneuploid cells Christopher M. Brennan, Laura Pontano Vaites, Jonathan N. Wells, et al. Genes Dev. August , 2019 33: 1031-1047

This article cites 16 articles, 7 of which can be accessed free at: http://genesdev.cshlp.org/content/33/15-16/1027.full.html\#ref-list-1

Articles cited in: http://genesdev.cshlp.org/content/33/15-16/1027.full.html\#related-urls

This article is distributed exclusively by Cold Spring Harbor Laboratory Press for the first six months after the full-issue publication date (see http://genesdev.cshlp.org/site/misc/terms.xhtml). After six months, it is available under a Creative Commons License (Attribution-NonCommercial 4.0 International), as described at http://creativecommons.org/licenses/by-nc/4.0/.

Receive free email alerts when new articles cite this article - sign up in the box at the top right corner of the article or click here.

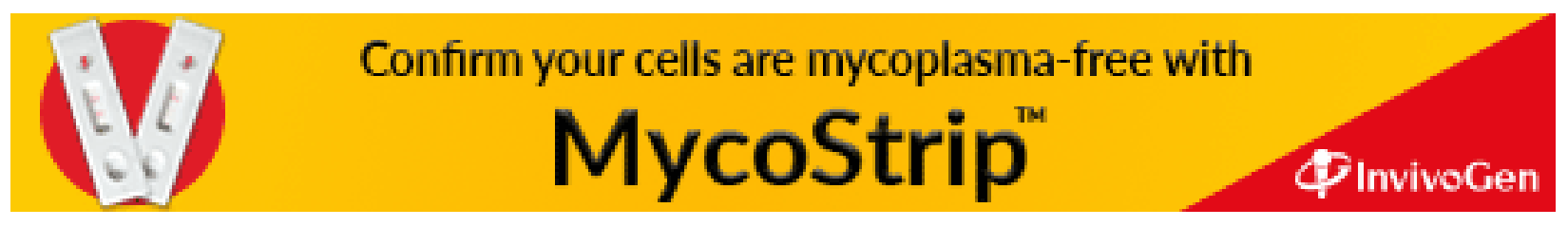

